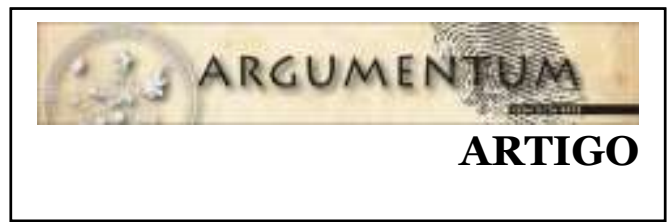

\title{
Redução de Danos na realidade do CAPS-ad de Quixadá (CE)
}

\author{
Harm Reduction in the reality of the CAPS-ad in Quixadá (CE)
}

Leandro Sobral de LIMA*

https://orcid.org/o000-0002-1950-1804

\section{Francisco Valberdan Pinheiro MONTENEGRO**}

http://orcid.org/o00o-0002-9898-5084

\begin{abstract}
Resumo: Esse texto apresenta uma discussão a partir da pesquisa de Trabalho de Conclusão da Residência Integrada em Saúde (TCR) com ênfase na saúde mental, tendo como objetivo principal analisar a compreensão da equipe multiprofissional do CAPS-AD de Quixadá (CE) sobre a política de redução de danos e sua relação com as ações desenvolvidas no cotidiano da instituição. A pesquisa realizada teve como abordagem a qualitativa e os instrumentos utilizados na coleta e análise dos dados foram: observação participante com registro em diário de campo; entrevista semiestruturada; pesquisa bibliográfica e análise de conteúdo. Como resultados principais, identificamos na fala dos interlocutores e nas práticas assistenciais a existência de uma compreensão crítica sobre a política de drogas no Brasil e, no entanto, um conhecimento superficial acerca da estratégia de redução de danos. Nota-se, ainda, os desafios cotidianos para colocar em prática formas de cuidado consonantes com a estratégia de redução de danos, para além da socialização de informações.
\end{abstract}

Palavras-chave: Drogas. Redução de danos. Saúde mental.

\begin{abstract}
This text presents a discussion based on research from the Conclusion Work for Integrated Residency in Health, with emphasis on mental health, and its main objective is to analyse the level of understanding of the multi-professional team of the CAPS-ad in Quixadá (CE) regarding the harm reduction policy and its relationship to actions developed in the institution's daily life. Qualitative research was carried out and the tools used in the collection and analysis of the data were: participant observation with recording in field diaries; semi-structured interviews; bibliographic research and content analysis. As the main results, from the speech of the interlocutors and in healthcare practices, we identified the existence of a critical understanding of drugs policy in Brazil and only a superficial knowledge regarding the harm reduction strategy. We also noted the daily challenge to, "put into practice", forms of healthcare in line with the harm reduction strategy, in addition to the socialisation of information.
\end{abstract}

Keywords: Drugs. Harm reduction. Mental health.

Submetido em: 31/3/2020. Aceito em: 9/7/2020.

\footnotetext{
* Assistente Social. Discente do Mestrado Acadêmico em Serviço Social, Trabalho e Questão Social na Universidade Estadual do Ceará. (UECE, Fortaleza, Brasil). av. Dr. Silas Munguba, 1700, campus do Ítaperi, Fortaleza (CE), CEP: 60.714.903 E-mail: leandro_liima@hotmail.com.

** Psicólogo. Residente Multiprofissional em Saúde Mental na Escola de Saúde Pública Visconde de Sabóia. (ESPVS, Sobral, Brasil). Av. Jonh Sanford, 1320, Sobral (CE), CEP: 62030-ooo. E-mail: tenegrodan@gmail.com.
}

\section{$(\mathrm{cc}) \mathrm{Br}$}

(C) A(s) Autora(s)/O(s) Autor(es). 2019 Acesso Aberto Esta obra está licenciada sob os termos da Licença Creative Commons Atribuição 4.0 Internacional (https://creativecommons.org/licenses/by/4.o/deed.pt_BR), que permite copiar e redistribuir o material em qualquer suporte ou formato, bem como adaptar, transformar e criar a partir deste material para qualquer fim, mesmo que comercial. O licenciante não pode revogar estes direitos desde que você respeite os termos da licença. 


\section{Introdução}

$\mathrm{O}$ consumo das substâncias psicoativas classificadas como drogas é uma prática trans-histórica, presente em todas as sociedades desde as tradicionais às contemporâneas. $\mathrm{O}$ consumo de psicoativos pode ter diversas finalidades como a busca de estados de êxtase, apreciação do divino, procura de prazeres ou como forma de lidar com o sofrimento. Nessa perspectiva, o consumo destas substâncias atende às necessidades humanas e assume finalidades distintas em cada sociedade, como os usos terapêuticos ou ritualísticos nas civilizações tradicionais ou usos recreativos nas sociedades contemporâneas.

Com o desenvolvimento do modo de produção capitalista, precisamente em sua era monopolista, o consumo de drogas passa a ser visto como um problema que deve ser controlado pelo Estado. No século XX as relações de produção, consumo e comércio que os seres humanos estabelecem com as substâncias psicoativas adquiriram proporções suficientes para fazer da questão das drogas ${ }^{1}$ um fenômeno global. Contiguamente, neste mesmo século, o paradigma proibicionista se consolidou por meio da hegemonia dos Estados Unidos da América através da Organização das Nações Unidas (ONU) e suas convenções, como uma ideologia que visa extinguir o uso de drogas, para acabar com a sua produção e construir uma sociedade abstinente (ALBUQUERQUE, 2018).

O caráter ideológico do Estado e da ciência, no que diz respeito ao uso de drogas, possibilitou por meio do estatuto médico-jurídico que o tratamento dispensado aos consumidores fosse, por muito tempo, o mesmo destinado às pessoas que possuíam algum tipo de diagnóstico psiquiátrico. Nesse aspecto, a lógica de aprisionamento e exclusão, que marcou de modo determinante a história da saúde mental no mundo e no Brasil, também é identificada nos tratamentos destinados aos sujeitos que usam e/ou abusam das substâncias psicoativas. Entretanto, a partir da segunda metade do século passado surgem questionamentos sobre a assistência psiquiátrica e as formas de tratamento centradas no controle, no confinamento e na punição dos então chamados loucos (FOUCAULT, 1997).

A partir das denúncias e da organização dos usuários e dos trabalhadores de saúde mental, a sociedade brasileira testemunhou a emergência dos movimentos da luta antimanicomial e da Reforma Psiquiátrica. O movimento social propulsor da reforma em questão foi o Movimento de Trabalhadores em Saúde Mental (MTSM), que logo se desdobrou em dois movimentos maiores e articulados: o Movimento de Luta Antimanicomial e o Movimento pela Reforma Psiquiátrica. Estes movimentos tinham como pauta principal a defesa de um novo modelo de assistência psiquiátrica em contraposição ao modelo asilar. Eles

\footnotetext{
${ }^{1}$ Quando falamos em questão das drogas tratamos de toda a problemática relacionada às drogas. Desde sua produção e consumo, até a ideologia proibicionista. Com base em (ALBUQUERQUE et al. 2016), tratamos a questão das drogas como uma expressão da questão social. Esse é o campo que se constrói ao redor de tudo aquilo que envolve a produção, o comércio e o consumo de algumas substâncias, as quais se convencionou chamar, não sem consequências, de drogas, conformando, dessa maneira, a questão das drogas.
} 
politizaram e materializaram a luta contra as formas desumanas de tratamento. Segundo Delgado (2005), "[...] o desrespeito aos direitos humanos dos pacientes foi, desde o início, o tema dominante das denúncias do MTSM" (DELGADO, 2005, p. 18).

Após a grande efervescência dos movimentos sociais no contexto da redemocratização do país, dentre esses aqueles específicos na área da saúde mental, surge no pós-constituição de 1988 uma nova forma de tratamento destinada aos pacientes com algum tipo de transtorno mental, em contraposição ao modelo hospitalocêntrico em vigor. A organização de militantes da saúde mental, trabalhadores, acadêmicos, usuários, organizações comunitárias e afins, acarretou no surgimento dos Centros de Atenção Psicossocial (CAPS) objetivando um cuidado humanizado, territorial e comunitário, diferente daquele realizado pelos hospitais psiquiátricos.

A vitória do Movimento de Reforma Sanitária, que reivindicava uma política de saúde pública e universal para todos, por meio da pressão da classe trabalhadora possibilitou a criação do Sistema Único de Saúde (SUS), algo de fundamental importância para o avanço das pautas antimanicomiais. Tendo em vista a compreensão ampliada de saúde e os princípios basilares do SUS como universalidade, integralidade e equidade no acesso à política de saúde, foi possível conquistar significativos avanços na política de saúde mental através da Reforma Psiquiátrica, sobretudo, no que diz respeito aos sujeitos e suas famílias, bem como na criação de serviços públicos destinados às pessoas em sofrimento mental.

Nesse processo, destacamos alguns marcos históricos como a aprovação da Lei 10.216/2001 e a criação e normatização dos CAPS com a portaria no 336/2002 do Ministério da Saúde. No campo específico das drogas, cabe destacar a Política de Atenção Integral a Usuários de Álcool e outras Drogas do Ministério da Saúde, em 2003; a criação dos CAPS-AD em 2004 e; a criação da Rede de Atenção Psicossocial-RAPS em 2011. Nesse ínterim, o Estado passa a intervir na questão das drogas não apenas como caso de polícia, mas reconhecendo o uso de drogas como uma questão de saúde pública e, portanto, como responsabilidade do Estado a oferta de políticas sociais. A partir de então, os serviços de saúde mental passaram a realizar o cuidado não mais tomando a abstinência como forma única de intervenção, mas também por meio da estratégia de Redução de Danos.

Dessa forma, podemos compreender a Redução de Danos como uma proposta alternativa de saúde pública para os modelos morais e criminais que abordam o consumo de drogas. Difere da perspectiva que considera a dependência como uma patologia biológica e, a abstinência total do uso como única meta aceitável no tratamento. A Redução de Danos compreende como irreal uma sociedade sem o consumo de drogas e, assim, busca reduzir os danos associados ao seu uso (BRITTES, 2006).

Em contrapartida, nos últimos anos vivenciamos um avanço exponencial do conservadorismo, expresso sobretudo, na erosão das instituições democráticas e no esvaziamento das instâncias de controle e participação social. Tais acontecimentos resultaram em uma maior moralização da questão das drogas e no aumento significativo do

Argum., Vitória, v. 12, n. 2, p. 238-252, maio/ago. 2020. | ISSN 2176-9575 
financiamento público para as Comunidades Terapêuticas (CT) (BRITTES, 2006; MONTENEGRO, 2018), entidades amplamente criticadas por profissionais de saúde, pois, além de representarem a privatização da saúde e o retorno do modelo asilar, fortalecem as propostas de recolhimento e internação involuntária como forma prioritária de tratamento (MACHADO, 2017).

Mesmo com o posicionamento da Organização Mundial de Saúde (OMS) em não reconhecer as CT, como espaço de tratamento adequado e orientar aos países que melhorem suas formas de fiscalização, observa-se o crescimento desse tipo de instituições. O Censo das Comunidades Terapêuticas realizado pelo Ministério da Justiça em 2014, aponta que existem 1.840 entidades dessa modalidade no país. Desse modo, corroboramos com Albuquerque quando afirma que:

No entendimento das organizações que compõem a Frente Drogas e Direitos Humanos, a proposta de realizar a atenção aos usuários de drogas pelas Comunidades Terapêuticas vai de encontro à Lei 10.216/2001 por terem como estratégias centrais para o cuidado: o isolamento social, a abstinência total e o trabalho forçado, além de ser um equipamento privado, que tem em sua maioria uma fundamentação religiosa imposta aos usuários (ALBUQUERQUE, 2018, p. 157).

Diante desse contexto, desvelar a compreensão dos profissionais inseridos em um CAPS$\mathrm{AD}$, sobre o consumo de substâncias psicoativas e formas de cuidado pautadas na redução de danos, se apresenta como algo relevante para o campo da saúde mental. Tendo em vista a produção teórica ainda bastante limitada na área das drogas, ao passo que profissionais se deparam cotidianamente com demandas relacionadas ao uso abusivo e/ou problemático de substâncias psicoativas que, muitas vezes, conduzem a práticas contraditórias entre a defesa de direitos e medidas de punição e controle dos usuários. Nesse horizonte analítico, conhecer, compreender e analisar as práticas assistenciais nos serviços de saúde mental frente à questão das drogas se torna bastante relevante. Assim, como as formas de articulação e de defesa de direitos no campo das políticas sobre drogas, que se apresentam como um debate fundamental e inadiável na atualidade.

Neste sentido, a pesquisa desenvolvida teve como objetivo principal analisar a compreensão da equipe multiprofissional do CAPS-AD de Quixadá (CE) sobre a política de redução de danos e sua relação com as ações desenvolvidas no cotidiano da instituição. Como forma de alcançar o objetivo principal, tivemos como desdobramentos alguns objetivos específicos: a) apresentar o percurso histórico da atenção aos usuários de drogas na política nacional de saúde mental; b) identificar a compreensão da equipe multiprofissional acerca da "questão das drogas" e; c) descrever as ações desenvolvidas pela equipe multiprofissional no campo da Redução de Danos.

Trata-se de um estudo de abordagem qualitativa. Elegemos como interlocutores os profissionais da equipe multiprofissional do CAPS-AD de Quixadá (CE), a saber: enfermeira,

Argum., Vitória, v. 12, n. 2, p. 238-252, maio/ago. 2020. | ISSN 2176-9575 
médico psiquiatra, assistente social e terapeuta ocupacional ${ }^{2}$. Após a submissão do projeto ao Comitê de Ética da Escola de Saúde Pública do Ceará e emissão do parecer favorável no 3.136.532, iniciamos a pesquisa de campo por meio da seguintes técnicas de coleta de dados: a observação participante com registro em diário de campo, a entrevista semiestruturada para aprofundar a apreensão do discurso dos interlocutores, além da pesquisa bibliográfica. Para a análise final dos dados coletados adotamos a técnica de análise de conteúdo.

\section{Desenvolvimento}

\subsection{Políticas de drogas no Brasil}

O consumo de substâncias psicoativas que foram classificadas como drogas é uma questão polêmica. $\mathrm{O}$ tabu que envolve as drogas perpassa por questões morais e sociais que determinam as formas de compreensão sobre o assunto, muitas vezes alicerçadas em juízos morais, ancoradas no senso comum. Esse tabu incide também nas formas de controle e de cuidado assumidas pelo Estado no gerenciamento do consumo de drogas. Sendo assim, o modo como o Estado lida com a questão das drogas se configura como um espaço de disputas de saberes e poderes acerca do direcionamento estratégico escolhido. Com isso, temos como horizonte a possibilidade de uma nova forma de lidar com a questão das drogas, com ênfase na liberdade e autonomia dos sujeitos.

O desenvolvimento da sociedade capitalista e os meios de socialização determinados pelo modo de produção acarretam numa busca constante pela felicidade plena através do consumo, lei geral desse sistema. O que permite no contexto sociopolítico atual que o uso de drogas possa ser analisado, também, como fenômeno da cultura de consumo fundamental para reprodução social (FERFFERMANN, 2006).

Diante disso, percebemos no contexto sociocultural e econômico da sociedade contemporânea um forte apelo à busca incessante pela felicidade plena, materializada no consumo de prazeres diversos, marcados, sobretudo, pela individualidade e o hedonismo (LIPOVETSKY, 2007). Nesse caso, a mesma sociedade que proíbe o uso de drogas, também produz a necessidade do consumo dessas mercadorias - seja como forma de pertencimento, seja como instrumento de alívio da dor ou busca de prazeres. Para além disso, quando tratamos da questão das drogas não podemos deixar de considerar os determinantes sociais, nas quais a maioria dos usuários estão inseridos. Como pontua Espíndola (2010):

Os processos de marginalização territorial e social, típicas do modo de produção capitalista, contribuíram para que indivíduos e suas famílias ficassem particularmente fragilizados, gerando mecanismos de violência e conflito social. A pouca oferta de empregos seguros, opções de lazer, fazem do comércio ilegal de drogas uma opção de sobrevivência para desempregados, usuários ou não de drogas ilícitas (ESPÍNDOLA, 2010, p.59-6o).

${ }^{2} \mathrm{O}$ serviço ainda conta em seu quadro profissional com 2 psicólogos, entretanto, não foi possível realizar a entrevista com nenhum dos psicólogos do serviço pois ambos estavam de férias no período de coleta de dados e realização das entrevistas.

Argum., Vitória, v. 12, n. 2, p. 238-252, maio/ago. 2020. | ISSN 2176-9575 
Neste contexto, mesmo com a lógica proibicionista em vigor, desde o início do século XX, o Relatório Mundial sobre Drogas da ONU divulgado em agosto de 2016 afirma que cerca de 5,6\% da população mundial entre 15 e 64 anos, o equivalente a 275 milhões de pessoas, usaram ou usam alguma droga elo menos uma vez ao ano (UNITED NATIONS OFFICE ON DRUGS AND CRIME, 2018). Assim, demonstrando que o impedimento-moralizante não tem diminuído, nem acabado com a busca por substâncias psicoativas.

No Brasil, a questão das drogas foi historicamente abordada a partir de uma perspectiva punitiva e disciplinadora das práticas sociais de determinados segmentos marginalizados. Não é por acaso que no ano de 1830, o município do Rio de Janeiro proibiu a venda e o uso do pito de pango (como era conhecida a maconha) através de um decreto numa ação clara de racismo e de tentativa de higienização da cidade (DAVID,2018). Apenas nas últimas décadas do século XX, a problemática passa a ser alvo também de políticas sociais e de cuidado, as quais passam a reconhecer o uso abusivo e/ou problemático de drogas como uma questão de saúde pública.

No que se refere às legislações federais que tratam sobre a questão no Brasil, isso ocorre em meados dos anos de 1961 após a aprovação em território nacional da Convenção Única de Entorpecentes. É no período de Ditadura Civil-Militar que a primeira lei³ (Lei № 6.368/1976) que trata sobre o controle penal do uso e do consumo é promulgada. Essa lei esteve vigente por mais de 30 anos quando foi enfim revista e então revogada pela Lei de drogas № 11.343/2006, que além de instituir o Sistema Nacional de Políticas Públicas sobre Drogas, trouxe ainda alguns avanços em relação à lei anterior como o reconhecimento da diferenciação entre usuário e traficante 4 e a Redução de Danos como uma forma de cuidado. Recentemente, ocorreu uma atualização da Lei de Drogas no Brasil. A nova legislação em vigor, a Lei 13.840/19, apresenta significativos retrocessos, sobretudo nas formas de tratamento e aumento de penas.

A apreensão do fenômeno do consumo de substâncias sob o viés médico-jurídico se perpetua até os dias de hoje como podemos perceber na reprodução da dualidade vítima/doente $\mathrm{X}$ traficante/delinquente encontrada na fala de uma dos profissionais:

[...] como a família não sabe lidar com esse usuário acaba que ela contribui. Ela contribui como? quando ela dar o dinheiro, né, quando ela permite que essa pessoa que ta doente é quem comanda aquela família. A família não se empodera de determinar que esse usuário ele é doente e ele precisa ser tratado, né (o2).

Essa leitura é permeada por compreensões ancoradas no senso comum, desde a posição do usuário como doente e que precisa de tratamento, independentemente de sua vontade, bem

3 Antes dessa Lei específica, o controle e punição que envolve a questão das drogas já existia, mas normatizado a partir de decretos.

4 Usamos o termo entre aspas porque a diferenciação entre usuário e traficante não está clara no corpo da lei. A diferenciação fica sob a chancela do policial no ato da abordagem ou do delegado. A realidade tem mostrado que a mesma quantidade de droga apreendida com um jovem branco de um bairro de classe média alta não possui o mesmo peso quando é apreendida com um jovem negro dos bairros periféricos.

Argum., Vitória, v. 12, n. 2, p. 238-252, maio/ago. 2020. | ISSN 2176-9575 
como pela culpabilização das famílias pelo processo de vulnerabilidade no qual se encontram. A partir da observação da realidade no serviço, não constatamos nenhuma ação direcionada especificamente para os familiares e/ou acompanhantes a não ser os atendimentos individuais ou demandas espontâneas. Essas observações tornam ainda mais claro o descompasso entre as conquistas dos movimentos de saúde mental e o dia a dia dos serviços de atenção psicossocial.

A partir do início do século XXI, com a aprovação da Lei 10.216/2001, tivemos avanços importantes do campo do cuidado em saúde mental aos usuários de drogas. No ano de 2002, tivemos a institucionalização dos Centros de Atenção Psicossocial. Já em 2003, temos a aprovação da Política de Atenção Integral aos Usuários Álcool e outras Drogas. O ano de 2005 é marcado pelo lançamento da portaria 1028, que trata sobre as ações de redução de danos. E, mais recentemente, em 2011, destacamos a criação da Rede de Atenção Psicossocial (RAPS).

Considerar o percurso histórico é de suma importância para que possamos visualizar o processo de constituição das formas de assistência à saúde dos usuários de substâncias psicoativas no SUS. Partindo dessa contextualização histórica, notamos que apesar de alguns avanços significativos na oferta do cuidado, a perspectiva proibicionista-punitivamoralizante permanece com força e se expressa, por exemplo, na busca pela diminuição da maioridade penal, na integração das Comunidades Terapêuticas à RAPS e, agora, de forma mais clara, com a possibilidade de internação involuntária como forma primária de tratamento.

Os Centros de Atenção Psicossocial (CAPS) são os serviços resultantes da luta pela Reforma Psiquiátrica, realizando serviço de atenção psicossocial para atendimento de pacientes com transtornos decorrentes do uso e dependência de substâncias psicoativas. Constituem-se como serviço ambulatorial de atenção diária e oferecem atendimento individual, familiar, grupal e terapêutico. Deste modo, o Centro de Atenção Psicossocial Álcool e outras Drogas (CAPS-AD) é o serviço público de assistência aos usuários de drogas e seus familiares. Nesse espaço, as equipes multiprofissionais devem trabalhar de forma complementar, considerando a complexidade das demandas dos usuários e do consumo de drogas, respeitando os direitos dos sujeitos, articulando a rede socioassistencial e não tendo mais a abstinência como única meta possível (ESPÍNDOLA, 2010).

O CAPS-AD, campo da pesquisa, está na cidade de Quixadá localizada no sertão central do Ceará a 168km da capital Fortaleza. Segundo o Instituto Brasileiro de Geografia e Estatística (IBGE), o município possui um população estimada em 87,728 habitantes. O serviço foi inaugurado no ano de 2011 e atende apenas a população do município em questão. Possui no seu quadro funcional auxiliar de serviços gerais, recepcionista, enfermeiro, médico psiquiatra, terapeuta ocupacional e psicólogos. A partir do ano de 2017, a Secretaria Municipal de Saúde estabeleceu uma parceria com a Escola de Saúde Pública do Ceará e a instituição passou a receber Residentes Multiprofissionais em Saúde Mental nas categorias de serviço social, educação física, psicologia, terapia ocupacional e enfermagem.

Argum., Vitória, v. 12, n. 2, p. 238-252, maio/ago. 2020. | ISSN 2176-9575 
No período da pesquisa, conforme constatamos por meio da observação participante no cotidiano institucional, o referido CAPS-AD tinha como algumas de suas principais atividades a realização dos atendimentos individuas e de acolhimento, nos quais eram fornecidas orientações sobre os possíveis efeitos e consequências do consumo de substâncias psicoativas (LIMA, 2015). Ainda nestes atendimentos, havia o compartilhamento de informações sobre saúde/qualidade de vida e repostas às eventuais dúvidas trazidas pelos usuários. Eram feitas recomendações básicas sobre alimentação e hidratação como formas de mitigar os danos fisiológicos do consumo de drogas; sobre o uso consciente, moderado ou responsável etc. Eventualmente, também a prevenção às Infecções Sexualmente Transmissíveis (IST) era abordada junto aos usuários por meio da distribuição de preservativos. Neste contexto, notamos que a disseminação das informações sobre atitudes favoráveis à saúde e redução de riscos e danos no uso de drogas durante os atendimentos, consultas e acolhimentos eram corriqueiras sem, no entanto, ocorrer de forma articulada e coordenada pela equipe.

Além dos atendimentos individuais, o serviço desenvolvia outras atividades como o Grupo de Tabagismo, cujo foco está na abstinência completa do cigarro tal como determina Programa Nacional de Controle do Tabagismo instituído pelo Ministério da Saúde. Havia também o Grupo de Prevenção à Recaídas, destinado aos usuários com problemas relacionados ao consumo de álcool. Ambos os grupos, até mesmo pelo perfil de usuários a que se dirigiam, enfatizavam a abstinência como principal horizonte do tratamento. Contudo, observamos que o paradigma da abstinência como meta se vê confrontado perante as necessidades apresentadas pelos usuários, como refere um dos profissionais entrevistados ao ser questionado sobre a forma de atuação diante da demanda de cuidado em torno de um quadro de abstinência:

Eu não vou chegar pro meu paciente que faz uso de álcool e dizer 'ó, ou você vai parar de beber ou você vai morrer' não é assim. Eu vou ter que ficar usando estratégias pra que ele se perceba. Que ele precisa reduzir o uso da substância (o3).

Essa fala demonstra que o paradigma da abstinência constitui um ideal que não se sustenta se considerarmos a realidade dos usuários, repercutindo também nas práticas assistenciais as quais deveriam responder tais demandas. Ainda do relato, podemos inferir a busca do interlocutor por uma apreensão da condição do usuário que não seja policialesca, porém considera a autonomia do usuário. Dessa forma, percebemos que não existe uma difusão do medo através de histórias inventadas, mas uma relação sincera com o usuário para que esteja sempre ciente do tratamento e das formas de cuidado. Isso se apresenta, também, quando os profissionais do serviço esclarecem os familiares sobre as internações e sobre a defesa de um tratamento no território, contrária a lógica de internação involuntária em vigor.

Hoje, vivenciamos um retorno à institucionalização dos usuários de drogas quando visualizamos como primeira estratégia, por parte de estados e municípios, práticas de internação involuntária ou compulsória de usuários de substâncias psicoativas em Comunidades Terapêuticas. Ou ainda, quando o tratamento ofertado para esses sujeitos se

Argum., Vitória, v. 12, n. 2, p. 238-252, maio/ago. 2020. | ISSN 2176-9575 
realiza de forma precária, tendo em vista o pouco investimento nas políticas de saúde e de saúde mental. Essa falta de investimento foi expressa por um dos interlocutores:

\begin{abstract}
Vejo também que os recursos que vem pros municípios são poucos, né. Não existe esse recurso pra você realmente trabalhar a prevenção e mesmo depois que esse usuário já está nesse...já está no uso, não existe, é, esse, não existe esse recurso, né, do município trabalhar com esse usuário, né, eu vejo que a política ela é bem bonitinha lá no papel. Os direitos estão lá, tem até a cartilha do usuário. Mas na verdade, na prática, ele deveria ser efetivado realmente, pelo menos nos municípios eu vejo essa política atuante (o2).
\end{abstract}

O contexto atual é marcado pela crise capitalista e pela financeirização da economia, pela reestruturação produtiva e políticas neoliberais. Neste escopo, as políticas públicas precárias e de controle social punitivo têm funcionado como instrumento de administração da pobreza na era do desemprego em massa e do trabalho precário (WACQUANT, 2008). Embora a ideologia proibicionista, que direciona hegemonicamente a atual política de drogas no país, apresente fissuras e contradições como a organização de movimentos sociais que começam a pautar a legalização das drogas, a dimensão punitiva e disciplinadora dos usuários de drogas permanece presente nas políticas sociais, inclusive no âmbito da saúde mental, adensadas pela incapacidade do Estado de dar respostas às demandas da sociedade.

Sobre a dita incapacidade do Estado em lidar com essa questão, também foi relatada na fala dos entrevistados quando questionados acerca da política de drogas e das formas de tratamento:

[...] a política girava em torno disso, dessa repressão do tráfico, né, deixando a desejar nessa parte, que eu acho que é fundamental. A prevenção. Acho que precisa trabalhar mais isso (o1)

[...] existe muitas políticas, mas na prática mesmo isso quase que inexiste para alguns municípios. A gente sabe dos direitos do usuário né, dele ter esse serviço qualificado, de ter essa equipe qualificada nos serviços. A gente sabe que a política, ela ta aí pra dar esse suporte tanto ao usuário como a família, mas na prática, na prática, eu vejo que isso quase inexiste (02).

Neste sentido, as falas acima demonstram que a equipe possui uma compreensão crítica acerca das ações adotadas pelo Estado não concordando com os cortes nas políticas sociais e, da maneira como os governos buscam agir sobre essa expressão da chamada questão social. Tal compreensão por parte de uma equipe multidisciplinar, inserida num serviço público no interior do estado voltado para usuários de drogas, é de fundamental importância para que o serviço realize o cuidado de forma comprometida com a ética e os direitos sociais e humanos da classe trabalhadora.

\title{
2.2 A Estratégia de Redução de Danos
}

No que se refere à estratégia de Redução de Danos, a Associação Internacional de Redução de Danos define como: "[...] medidas que buscam prevenir ou reduzir as consequências negativas à saúde, associadas a comportamentos de risco como o uso de drogas" (INTERNATIONAL HARM REDUCTION ASSOCIATION, 2010). Assim, a redução de danos

Argum., Vitória, v. 12, n. 2, p. 238-252, maio/ago. 2020. | ISSN 2176-9575 
não implica necessariamente a abstinência de substâncias psicoativas, mas a busca por alternativas reais de usos menos prejudiciais à saúde dos usuários. Ou seja, essa perspectiva compreende e aceita a existência de usuários que não querem, não podem ou não conseguem parar o consumo de drogas (ESPÍNDOLA, 2010).

Na Europa, mais precisamente na Holanda no ano de 1984, contrário às posições da ONU sobre o consumo de drogas, foi implantado o primeiro programa de troca de seringas, bem como terapias de substituição de drogas e a formação de agentes multiplicadores de informações com foco na qualidade de vida dos usuários. Com a epidemia do HIV/AIDS ao redor do mundo e a constatação da transmissão do vírus em usuários de drogas injetáveis, que compartilhavam seringas, a estratégia da Redução de Danos ganha espaço e passa a ser utilizada no Brasil, em 1989 na cidade de Santos, localizada no interior do estado de São Paulo (RIBEIRO, 2012).

Acerca do processo histórico da redução de danos no Brasil, temos o primeiro programa de trocas de seringas em 1989 na cidade de Santos (SP) e sete anos depois um programa semelhante no ano de 1996 em Salvador (BA), mesmo ano de fundação da Associação Nacional de Redutores de Danos (ABORDA) e, em 1998 a Rede Brasileira de Redução de Danos (REDUC). Assim, no início do século XXI, a experiência brasileira da Redução de Danos era referência para os demais países da América Latina e mostrava resultados importantes no país, como a redução no número de casos de contaminação pelo HIV entre Usuários de Drogas Injetáveis (UDI) em 62\%, de acordo com dados do Boletim Epidemiológico de DST/Aids 2005 depois de dez anos do início das ações de trocas de seringas (ROSA, 2014).

Ademais, é interessante percebermos como os assuntos referentes às drogas sempre foram secundarizados no campo da saúde. Enquanto a política de saúde mental avançava por meio da Lei 10.216/2001 (BRASIL, 2001), apenas em 2006 temos alguns avanços no campo de drogas com a Lei 6.343/2006. Além disso, a própria implementação de ações de redução de danos só foram possíveis dada preocupação com a epidemia HIV/Aids, sem a qual não poderiam ter sido institucionalizadas. Portanto, percebemos que ainda há muito o que percorrer no Brasil quando o assunto é a questão das drogas e as formas de cuidado. Sobre a política de Redução de danos, os entrevistados revelaram:

Eu acho que não precisa parar. Só a redução de danos é muito importante. É o primeiro passo e um passo fundamental na vida deles (03).

Eu acho que essa política deveria ser mais difundida. Levada com cautela para as instituições e profissionais se instruir mais (04).

[...] das pessoas realmente saber que existe essa política, porque nem eles realmente sabem a maioria das famílias não sabem que ele pode ta reduzindo esse dano, né, dessa forma e a família é muito pobre de informação, eu vejo assim. Principalmente quem tem usuário. Ela acha que so o fato dele usar é que vai causar o problema maior. Ela não vê que ele fazendo essa redução de danos vai ser melhor pra todo mundo. Tanto pra ele, como pra família. E pra sociedade de uma forma geral (o2).

Argum., Vitória, v. 12, n. 2, p. 238-252, maio/ago. 2020. | ISSN 2176-9575 
Considerando as falas dos interlocutores é possível apreender que a equipe busca trabalhar tendo a redução de danos, como um dos instrumentos disponíveis para um melhor cuidado dos usuários. Mesmo com todas as dificuldades vivenciadas em um serviço precário, sem condições éticas e técnicas para o trabalho com a redução de danos, sem investimentos na área e em uma cidade do interior cearense, destacamos a preocupação da equipe com a educação permanente para um melhor atendimento e cuidado.

Partindo das leituras teórico-técnicas em articulação com a pesquisa de campo realizada, foi possível perceber que os entrevistados procuram desenvolver o trabalho numa perspectiva de respeito ao direito dos usuários e na divulgação de informações. O que consideramos um dos princípios da redução de danos e um dos maiores desafios no cenário atual. Contudo, os achados da pesquisa não permitem afirmar que havia um conhecimento substancial sobre estratégia de Redução de Danos (RD) integrado aos modos de produzir o cuidado no referido CAPS-AD.

Cabe pontuar que existe a necessidade de um melhor conhecimento acerca da estratégia de $\mathrm{RD}$, tendo em vista que não se resume a divulgação de informações sobre os efeitos das drogas, ou a distribuição de insumos como camisinhas, quando o serviço possui. A estratégia de RD é compreendida como uma ética do cuidado, como uma forma de abordagem e ação política que vai muito além do que é realizado na maioria dos serviços de saúde mental, particularmente, no CAPS-AD de Quixadá (CE). Com isso, a educação permanente em saúde deve ser um instrumento estratégico para a lapidação das compreensões das equipes e para qualificar a atuação multidisciplinar.

Em 2015, a política de saúde mental passou a vivenciar uma contrarreforma psiquiátrica, não somente nos investimentos para estrutura e educação permanente, mas também ao financiamento da RAPS. Assim, observamos mudanças de rumo drásticas sobre a perspectiva do cuidado. Atualmente, em consequência de uma necropolítica belicista, manicomial e racista no campo da política de drogas e da saúde mental vivenciamos uma conjuntura completamente desfavorável para os usuários de substâncias psicoativas que buscam o SUS.

A nova Lei de Drogas aprovada continua não somente alinhada à ideologia proibicionista, porém houve um recrudescimento punitivo com ampliação de penas e um redirecionamento das políticas de cuidado para o foco na abstinência. Houve também o fortalecimento do estereótipo médico-criminal por meio do acirramento da dualidade traficante-perigoso e usuário-doente, cuja classificação é mediada pelos marcadores de classe e raça. Além disso, a norma prevê internações involuntárias subsidiadas pelo amplo investimento em Comunidades Terapêuticas como espaços de tratamento. Diante deste cenário adverso, é de suma importância fortalecer a política de Redução de Danos como uma ética de cuidado centrada na produção da vida.

Argum., Vitória, v. 12, n. 2, p. 238-252, maio/ago. 2020. | ISSN 2176-9575 


\section{Considerações finais}

Como já pontuamos anteriormente, a questão das drogas é um assunto polêmico e, na maioria das vezes, é compreendido a partir de um viés moralizante-religioso e/ou criminal. Neste estudo, buscamos perspectivar a questão das drogas de forma crítica, livre de julgamentos pré-estabelecidos e, ao mesmo tempo, analisar como a problemática se apresenta no movimento da realidade do CAPS-AD de Quixadá (CE).

A partir da pesquisa realizada constatamos que os cortes na política de saúde 5 têm repercutido diretamente na vida dos sujeitos que mais precisam de cuidado e atenção, sobretudo, os usuários da política de saúde mental. Também comprova-se mais uma vez a insuficiência de investimentos consistentes nessa área. E, mesmo com todas as dificuldades experimentadas (falta de material, de espaço físico adequado, dentre outros) a equipe multiprofissional do CAPS-AD realiza um trabalho no campo do cuidado e, na oferta dos serviços com respeito aos sujeitos e seus familiares.

No que se refere a Política de Redução de Danos, entretanto, as práticas assistenciais observadas e seus reflexos nas falas dos participantes não permitem caracterizar uma atenção plenamente orientada pela lógica da estratégia de RD e, muito menos, um domínio teórico-técnico sobre a RD, bem como sobre as legislações e portarias específicas. Visualizamos ainda, a necessidade de fortalecer a RD enquanto ética do cuidado tendo em vista o aumento do uso problemático de substâncias psicoativas e, ao mesmo tempo, o fortalecimento dos investimentos em ações repressoras por meio da segurança pública e formas conservadoras de tratamento. A aprovação da Lei 13.840/19, além de facilitar a internação involuntária de usuários integra as Comunidades Terapêuticas à RAPS e recrudesce o encarceramento para os mais pobres.

Reiteramos que uma perspectiva simplista na análise da questão das drogas, sem considerar suas determinações fundamentais, não nos permite avançar no debate, ou seja, que as drogas são mercadorias inseridas nas relações sociais capitalistas e daí a necessária moral proibicionista valorizando o mercado ilegal e criminalizando os indesejáveis para o capital. Assim, a RD é uma direção ético-política do cuidado, um compromisso com a liberdade e a autonomia dos sujeitos e uma pedagogia centrada nos direitos humanos.

\section{Referências}

ALBUQUERQUE, Cynthia Studart. Drogas, “Questão Social” e Serviço Social: respostas teórico-políticas da profissão. 2018. Tese (Doutorado em Serviço Social)-Universidade Federal do Rio de Janeiro, Rio de Janeiro, 2018.

ALBUQUERQUE, C. S; GOLÇALVES, A. M. Drogas e Proteção Social: os desafios da intersetorialidade. Fortaleza: Expressão, 2016.

5 Vale pontuar que a pesquisa foi desenvolvida ainda fora do contexto dos cortes mais severos nas políticas sociais.

Argum., Vitória, v. 12, n. 2, p. 238-252, maio/ago. 2020. | ISSN 2176-9575 
INTERNATIONAL HARM REDUCTION ASSOCIATION. O que é Redução de Danos? Uma posição oficial da Associação Internacional de Redução de Danos. Londres, 2010. Disponível em:

https://www.hri.global/files/2010/o6/o1/Briefing_what_is_HR_Portuguese.pdf. Acesso em: 18 ago. 2020.

BRASIL. Lei no 13.840, de 5 de junho de 2019. Brasília (DF), 2019.

Disponível em: http://www.planalto.gov.br/ccivil_03/_ato20192022/2019/lei/L13840.htm. Acesso em: 25 set. 2019.

BRASIL. Lei no 10.216, de 6 de abril de 2oo1. Dispõe sobre as condições para promoção, proteção e os direitos das pessoas portadoras de transtornos mentais e redireciona o modelo assistencial em saúde mental. Brasília (DF), 2001. Disponível em:

http://www.planalto.gov.br/ccivil_03/leis/leis_2001/l10216.htm Acesso em: 5 out. 2019.

BRASIL. Ministério da Saúde. A política do Ministério da Saúde para Atenção Integral aos Usuários de Álcool e outras Drogas. Brasília (DF), 2003. Disponível em: http://bvsms.saude.gov.br/bvs/publicacoes/politica_atencao_alcool_drogas.pdf. Acesso em: 6 out. 2019 .

BRITES, C. M. Ética e uso de drogas: uma contribuição da ontologia social para o campo da saúde pública e da redução de danos. 2006. Tese (Doutorado em Serviço Social)Programa de Pós-Graduação em Serviço Social da Pontifícia Universidade Católica de São Paulo, São Paulo, 2006.

CENSO DAS COMUNIDADES TERAPÊUTICAS NO BRASIL. Porto Alegre: Universidade Federal do Rio Grande do Sul, [2014]. Disponível em:

https://www.ufrgs.br/labgeo/index.php/projetos-concluidos/229-censo-dascomunidades-terapeuticas-no-brasil. Acesso em: 6 out. 2019.

DAVID, Juliana França. Breve Histórico e Evolução das Legislações referentes a Drogas no Brasil. Disponível em: https://emporiododireito.com.br/leitura/brevehistorico-e-evolucao-das-legislacoes-referentes-a-drogas-no-brasil. Acesso em: 10 ago.2019.

DELGADO, Pedro Gabriel. Drogas: o desafio da saúde pública. In: DROGAS, Aids e direitos humanos. Rio de Janeiro: Fiocruz 2005.

ESPÍNDOLA, L. F. G. Redução de Danos: uma análise da prática profissional dos assistentes sociais nos Centros de Atenção Psicossocial em Álcool e Outras Drogas do Recife. 2010. Dissertação (Mestrado em Serviço Social)-Universidade Federal de Pernambuco, Recife, 2010.

Argum., Vitória, v. 12, n. 2, p. 238-252, maio/ago. 2020. | ISSN 2176-9575 
FERFFERMANN, Marisa. Vidas arriscadas: o cotidiano dos jovens trabalhadores do tráfico. Petrópolis: vozes, 2006.

FOUCAULT, Michel. A História da Loucura na Idade Clássica. São Paulo: Perspectiva, 1997.

LIMA, Leandro Sobral de. “Se eles não vieram pra cá, pra onde eles irão?”: desafios para o processo de "reinserção social" no caps-ad de Iguatu (CE). 2015. Monografia (Trabalho de Conclusão do Curso de Bacharelado em Serviço Social), Instituto Federal do Ceará campus Iguatu, 2015.

LIPOVETSKY, Gilles. A felicidade paradoxal: ensaio sobre a sociedade de hiperconsumo. São Paulo: Companhia das Letras, 2007.

MACHADO, L. Ação de limpeza na cracolândia tem reforço policial e desloca usuários para o Centro de SP. O Globo, São Paulo, 19 jul. 2017. Disponível em:

https://g1.globo.com/sao-paulo/noticia/acao-de-limpeza-na-cracolandia-tem-reforcopolicial-e-desloca-usuarios-pelo-centro-de-sp.ghtml. Acesso em: 5 ago. 2019.

MONTENEGRO, Francisco Valberdan Pinheiro. O dispositivo das drogas nas políticas públicas. Rev. Polis Psique, Porto Alegre, v. 8, n. 2, p. 263-287, ago. 2018. Doi: 10.22456/2238-152X.73638. Disponível em:

https://seer.ufrgs.br/PolisePsique/article/view/73638. Acesso em: 14 maio 2019.

RIBEIRO, Maurides de Melo. Drogas e redução de danos: análise crítica no âmbito das ciências criminais. 2012. Tese (Doutorado de Direito)-Faculdade de Direito da Universidade de São Paulo, São Paulo, 2012.

ROSA, Pablo Ornelas. Drogas e a governamentabilidade neoliberal: uma genealogia da redução de danos. Florianópolis: Editora Insular, 2014.

UNITED NATIONS OFFICE ON DRUGS AND CRIME. Relatório Mundial sobre Drogas 2018: crise de opioides, abuso de medicamentos sob prescrição; cocaína e ópio atingem níveis recordes. Disponível em: https://www.unodc.org/lpobrazil/pt/frontpage/2018/o6/relatorio-mundial-drogas-2018.html. Acesso em: 5 ago. 2019.

WACQUANT, Loic. As Duas Faces do Gueto. Tradução de Paulo Cezar Castanheira. São Paulo: Boitempo, 2008. 
Leandro Sobral de LIMA Trabalhou na concepção e delineamento do trabalho e na redação do artigo. Assistente Social graduado pelo Instituto Federal do Ceará (IFCE-campus Iguatu). Especialista em Saúde Mental Coletiva pela Escola de Saúde Pública do Ceará (ESP-CE). Discente do Mestrado Acadêmico em Serviço Social, Trabalho e Questão Social (MASS-UECE).

Francisco Valberdan Pinheiro MONTENEGRO Trabalhou na redação do artigo e na revisão crítica. Psicólogo graduado pela Universidade Federal do Ceará (UFC). Residente Multiprofissional em Saúde Mental na Escola de Saúde Pública Visconde de Sáboia (ESPVS). 